\title{
HEAVY ROLLING MILL AUTOMATION PROPOSAL WITH UTILIZATION OF DIGITAL IMAGE PROCESSING
}

\author{
Andrei LAPTEV, Cristian PETRACHI, Jan MINARČíK, Barbora ČAPKOVÁ, Jan POLÁŠEK, \\ Nikita STRATINSKIY \\ VSB - Technical University of Ostrava, Ostrava, Czech Republic, EU, \\ andrei.laptev.st@vsb.cz, cristian.petrachi.st@vsb.cz, jan.minarcik@vsb.cz, barbora.capkova.st@vsb.cz, \\ jan.polasek@vsb.cz, nikita.stratinskiy.st@vsb.cz
}

https://doi.org/10.37904/metal.2021.4277

\begin{abstract}
The modern metallurgical industry characterized by increased requirements for quality, economy and efficiency of technological processes. Automation based on a systematic approach to problem solving, it focuses on improving technical means, increasing labor productivity and improving product quality. The ultimate goal is to create automatic systems, which operate without human intervention. The article contains a description of the current state of the heavy rolling mill and a proposal for the automation of its individual components. The main goal of the article is to show the use of a camera system and artificial intelligence in the automation of heavy industry processes. To automate the rolling process on a heavy rolling mill, a machine vision will be used with the help of a laser camera system with digital image processing on rolling wagons used for handling with a rolling bar. This is used for the transfer of the rolled bars between the individual stands and between the rolling calibers within the rolling mill stands. The intended automation of the operation follows the Industry 4.0 trend, which is beginning to inspire even these heavy operations. The concept of an automation system based on artificial intelligence and utilization of machine vision is in great demand and it is possible to expect the rapid development of these scientific fields. The article will also focus on issues, which prevents the use of standard commercial solutions. As part of the feasibility analysis, the conditions prevailing in profile rolling were analyzed. The biggest challenge was the presence of steam in the area of the rolling mill stand, which makes it impossible to precisely guide the rolled bars between the rolling calibers.
\end{abstract}

Keywords: Heavy rolling mill, camera system, automatization

\section{INTRODUCTION}

The aim of the article is the observation and writing of the current state of the heavy rolling mill (HRM) and to design an automation control of rolling wagons and control actuators HRM with the help of a camera system. The heavy profile track put into operation in 1914 has undergone several major upgrades since this time. The new modifications should make it possible to control all functions that are currently performed from 4 cabins directly in the wagons, from one central workstation in the cab of the metal-rolling specialists K3. The expected benefit is a decrease in operating costs and an increase in the operational safety of HRM.

\section{DESCRIPTION OF THE CURRENT STATE}

The Figure 1 shows the general layout of technologies and cabins for controlling the rolling process.

The rolling mill consists of 4 reversible duo mill stands. 4 rolling wagons are used for the transverse transfer blocks between the mill stands. The basic technical equipment of the profile rolling mill includes, in particular, the Stepping Grate, Presser, Planting Grate, Blast Furnace, Rolling transport wagons, Reversible rolling mills stands, Heat saw heat and Cooler. 
The article will focus primarily on rolling wagons.
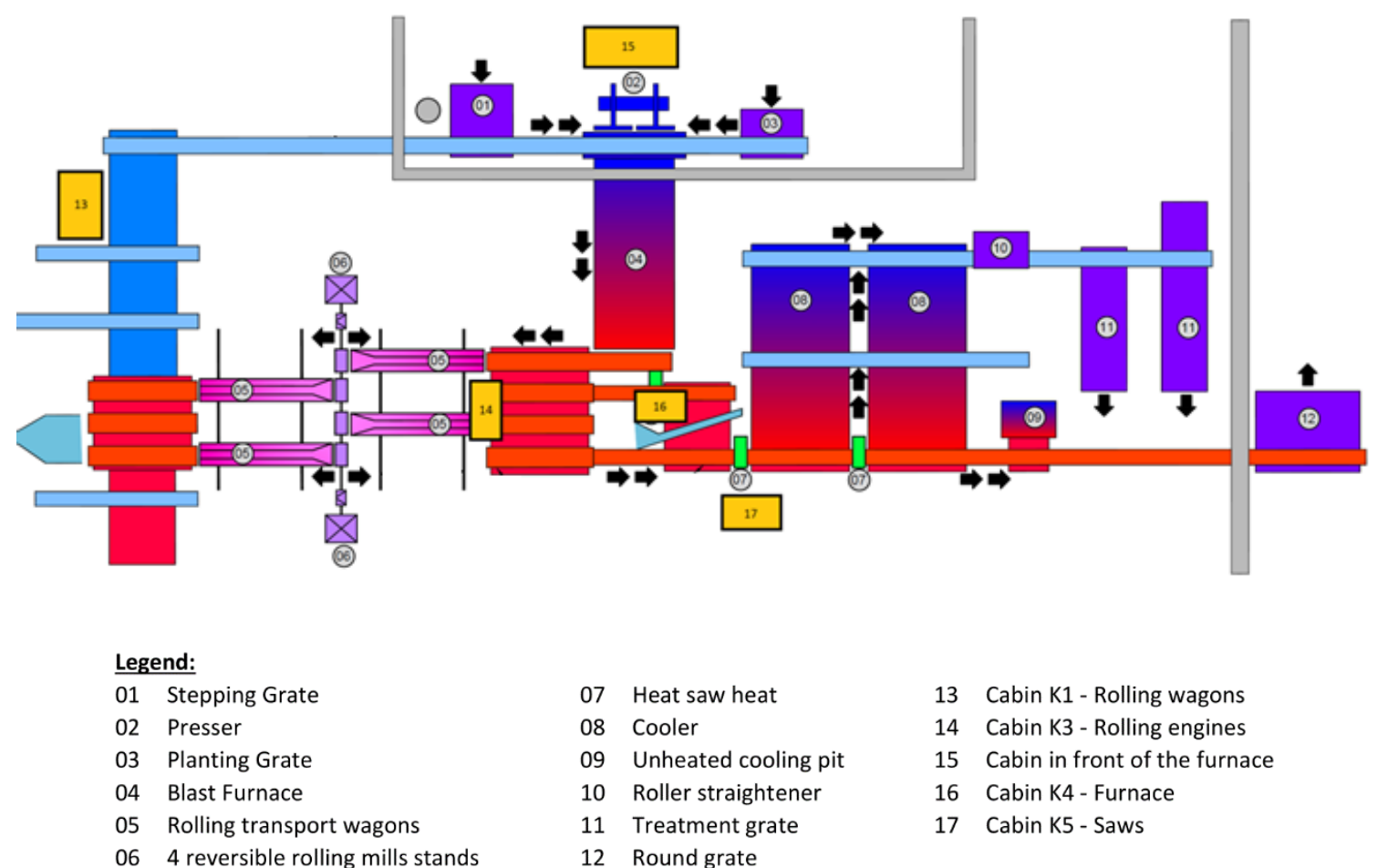

$\begin{array}{ll}07 & \text { Heat saw heat } \\ 08 & \text { Cooler } \\ 09 & \text { Unheated cooling pit } \\ 10 & \text { Roller straightener } \\ 11 & \text { Treatment grate } \\ 12 & \text { Round grate }\end{array}$

13 Cabin K1 - Rolling wagons

14 Cabin K3 - Rolling engines

15 Cabin in front of the furnace

16 Cabin K4 - Furnace

064 reversible rolling mills stands

12 Round grate

Figure 1 HRM device layout. Source: [own processing]

\section{Description of the production process}

The main production program of HRM is mainly sheet piles, but there can also be rolled profiles of other types. Sheet piles are rolled from a basic block of prescribed length and rectangular cross-sections. The basic blocks intended for rolling sheet piles are through Step planting grate 01, the Planting Grate 03 and the Presses 02 gradually inserted into the Blast Furnace 04 . Since the "HRM" operation for heating the block is equipped with a blast furnace, it is necessary to insert "dams" between the individual blocks, to avoid "stick" of the two blocks to each other. The dams are not intended for rolling - they usually have a square cross-section so that they are easily recognizable from the blocks to be rolled.

The basic working "tact time" of the blast furnace is 6 minutes. The operating "tact time" is not fixed by the control system, but all the operations of the blast furnace are controlled by the furnace operator based on the completion of the previous rolling process. The control of the device is performed from the cabin in front of the furnace.

After the hot block falls out of the impact furnace on the roller flatbed behind the furnace, the hot block is transported to the tedder. The main task of the tedder is to turn the hot block intended for rolling at angle of $90^{\circ}$. Blocks unsuitable for rolling (which are bent and otherwise damaged) are turned at angle of $180^{\circ}$ and "dams" do not turn at all. At the same time, there is considerable descaling at this point. The flatbed behind the furnace is controlled from cabs $\mathrm{K} 3$ and $\mathrm{K} 4$, the tedder from cab K4.

The block determined to be rolled, turned at angle of $90^{\circ}$, by help of a flatbed is between the tedder and rolling wagon No. 2. and is then transported to the flatbed of rolling wagon No. 2. This flatbed can be controlled from cabs K3 and K4. Blocks unsuitable for rolling and "dams" are also moved from the tedder to the flatbed of rolling wagon No. 2. [1] 
The primary task of rolling wagons 05 are to perform all manipulations with blocks intended for rolling. They are mainly used to perform:

- $\quad$ transverse manipulations with the rolling bars, i.e., movements of the rolled block between the individual stands and between the rolling calibers within the rolling stand. Based on long-term observation and examination of the production-technological process of rolling sheet piles, it was concluded that only this activity can be automated to a certain extent;

- $\quad$ inversion of the block on the flatbed of the rolling wagon, "edging". The execution of this productiontechnological operation is governed by the rolling prescription and is performed only on rolling wagon No. 2 and No. 1. This work activity of the rolling wagon cannot be automated, it must always be performed by the operator;

- $\quad$ beveling, its partial rolling of the tip of the block for the purpose of easier further introduction of the block into the caliber of the rolling mill stand. The execution of this production-technological operation is governed by the rolling prescription and is performed only on rolling wagon No. 2 and No. 1. This work activity of the rolling wagon cannot be automated, it must always be performed by the operator;

- directing the flow of the rolling bar during the rolling process itself, both during the introduction of the rolling bars into the caliber of the rolling mill stand and during the exit of the rolling bar from the caliber of the rolling mill stand. The flow control is performed both by corrective transverse displacements of the rolling wagon along the rail, and by help of the movements of the "swing table" of the rolling wagons. The implementation of these production operations is carried out only on the basis of practical experience and knowledge of rolling mill operators from the sheet pile rolling process. This work activity of the rolling wagon cannot be automated, it must always be performed by the operator. $[2,3]$

Operation "HRM" is equipped with a total of 4 rolling wagons 05 , marked with numbers 1 to 4 . The basic production and technological equipment of the "HRM" operation consists of 4 rolling mill stands 06 , marked with numbers 1 to 4 , driven by two asynchronous motors through the gearbox. Two rolling wagon are located on a common track in front of the rolling mill stand (No. 1 and 3) and two other wagons on a common track behind the rolling mill stand (No. 2 and 4). Each rolling wagon is operated by one operator directly from the rolling wagon cab, where there are two control panels. Each rolling wagon is able to serve 3 rolling mill stands if another wagon on a common track is situated at the end of the track.

The rolling process always starts with wagon No. 2, which is able to operate rolling mill stand No. 1, 2 and 3. On the other side, behind rolling mill stand No. 1, 2 and 3, it is assisted by wagon No. 1. The wagons perform all manipulations with a hot block and then with a pre-roll according to the rolling regulation. Wagon No. 2 introduces the block into the appropriate caliber of the relevant rolling mill stand according to the regulation, wagon No. 1 on the opposite side "catches" this block. Wagon No. 1 stands opposite wagon No. 2, opposite the relevant caliber of the relevant rolling mill stand according to the rolling prescription. During the rolling process, their own flatbeds are activated on both rolling wagons, which rotate in the direction of movement (introduction) of the block into the rolling mill stand. When the passage of the block through the caliber through the rolling mill stand is fully completed, the process is stopped on the flatbed of wagon No. 1 and the function is reversed. After performing the necessary production-technological operations, like "edging" or "beveling" and placing the main rolling rolls on the stand according to the rolling prescription, will then be transporting the rolling bar into the appropriate caliber of the respective rolling mill stand, wagon No. 1 and wagon No. 2 will "catch" the rolling bar. The two wagons must move together transversely, the rolling process according to the rolling prescription requires the passage of the pre-roll through another caliber of the rolling rolls or the transition to the second rolling mill stand.

Rolling process in the same way complete the rolling wagons No. 3 and 4. Transverse travel of wagons No. 3 and 4 along the railway track is enabled at rolling mill stand No. 4, 3 and 2, where they perform productiontechnological operations with a roll bar according to the rolling prescription. The whole rolling process ends 
with rolling wagon No. 4, which then transports the finished product - the sheet pile to the flatbeds to the cutting saws. The total length of the finished sheet pile reaches approx. $80 \mathrm{~m}$. During the process of dividing the rolled sheet pile into shipping lengths, the sheet pile reaches up with its length to the flatbed of rolling wagon No. 4. The rolling mill stands are driven by two DC motors, which are controlled by rollers from the K3 cabin. The rolling process always takes place according to the rolling prescription, with which all operators are acquainted and carry out production and technological activities in accordance with this regulation. During the montage of the roll, the introduction of the block into the caliber is blocked. The current system relies only on light signaling using traffic lights at stands No. 2 and No. 4, or on the knowledge of rolling wagon operators No. 2 and No. 1 in the case of rolling mill stand No. 1. [1]

\section{CONSEQUENCES AND EFFECTS ON ENVIRONMENTAL TECHNOLOGICAL EQUIPMENT}

The proposal of the solution to automate the transverse crossings of rolling wagons must also take into account the following correlations with the surrounding technological equipment. For example: the ejection of a hot block from the blast furnace and the subsequent transport of the block or "dam" between the blast furnace and rolling wagon No. 2 must be blocked in the mode of automated transverse crossings, the rolling wagon will not be in its basic position for the transport of blocks or dams from the inverter to the flatbed of another rolling wagon.

The process of automated transverse crossings of rolling wagons with a hot block: The process begins with rolling mill No. 2 and can be started if the presence of hot material on the rolling wagon flatbed is detected. When the block is already inserted into the inlet of the appropriate caliber, the block has left the wagon flatbed and the flatbed rollers which rotate towards the rolling mill stand, must be automated laterally. The loading wagon also must be blocked immediately and must be only manual. This allows the wagon roll to be guided correctly to the gauge of the rolling mill stand, enabling correct guiding of the rolling bars to the caliber of the rolling mill stand. The insertion of the block into the caliber of the rolling mill stand can not be performed unless the mutual collinear position of the two cooperating wagons is ensured, the two cooperating wagons must always stand "opposite each other".

When the block is in the process of rolling, the transverse movement of the rolling wagon, which the rolling bar "catches", must be blocked, until it is clear that the rolling bar has already left the inlet of the relevant caliber and that the entire rolling bar is already on the rolling wagon flatbed. During the "catching" of the roll bar, it must be only manual correction of the wagon, which enables the correct guiding of the roll from the caliber of the rolling mill stand to the flatbed of the wagon or on the flatbed behind the wagon. This locks the flatbed on each rolling wagon when the rolling rolls are being built on the rolling mill stand, blocking the transverse crossing of rolling wagon No. 4 during the division of the finished sheet pile into final shipping lengths. $[4,5]$

\section{PROPOSAL OF ROLLING STOCK AUTOMATION}

\section{Control of rolling wagons}

Observations of the process have shown that full automation of the movement of the wagons during rolling is not possible.

Can be automated:

- crossing of the rolling wagon to the assumed axes of the profile rolling positions

- crossing of the rolling to the basic position and to the pass position

- crossing of the rolling to the safety position, etc.

Crossing of the rolling wagon can be initiated automatically with confirmation or manually. It is based on the fact that the rolling wagon should always stop automatically in the same approach positions with a defined 
tolerance - stopping offset. When inserting the roll into the profile it is necessary to take the actual position on the rolling wagon, curvature, etc. Based on visual monitoring by the camera system, it must be possible to correct the stopping of the rolling wagon by manual intervention. Setting up the entire system should minimize the number of manual operator interventions. The movement of the roll on the run-out side must be visually observed and, if necessary, correcting the direction by the travel of the vehicle or rocking table, etc. The controlled (corrected) movements are not simultaneous, they gradually follow each other. Immediately following each others introduction into the profile and subsequent rolling. Control by one operator should be an advantage. The condition is perfect for information for the operator about the state on the track through the camera system and visualization of the position of the roll on the rolling wagon. [4]

\section{Laser camera system}

The control of the position of the rolling wagon in relation to the rolling mill stand will be ensured by optical analysis of the image from the installed cameras. A system of high-resolution with digital cameras and auxiliary laser emitters will be used, which will guarantee precise calibration of the positioning system. The operator will have a comprehensive view of the rolling mill stand from individual wagons on a large screen. Advanced analysis of the images will be running on a specialized server, which will determine the relative position of the bar and rolling mill stand. Analytical information will be projected into the actual image from the cameras, for better orientation for the operator. The system will record image data to verify operating conditions and other information for future use. $[6,7,8]$

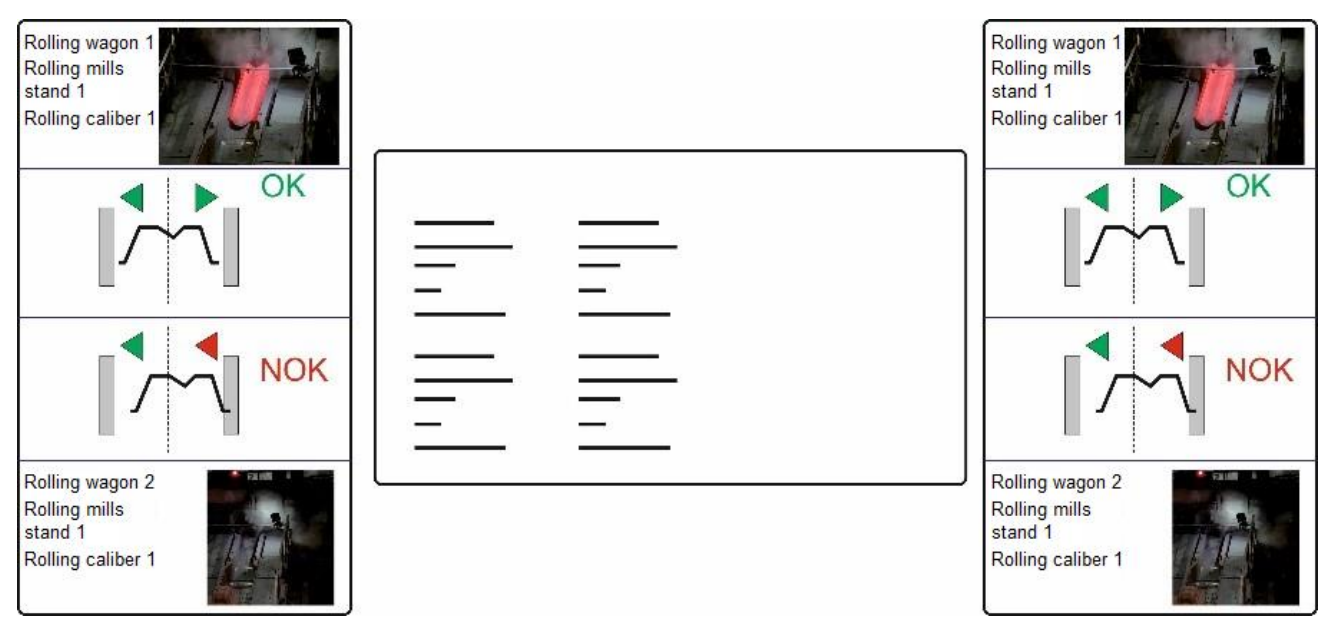

Figure 2 Laser camera system. Source: [own processing]

The principle of determining the position of the rolled slab before entering the stool is derived from determining the profile of the object using a laser line. The line laser is projected onto the object from top to bottom. On the object a reflected beam is visible, which copies its surface structure - profile. The image is periodically captured using an industrial camera and sent via Ethernet for processing. Image processing can be performed analytically or using an artificial neural network. Even for an artificial neural network, the input image needs somehow to be modified. In this case from the image only the part of the figure that corresponds to the red component will be used. A classic image consists three color components, defined by pixels and the corresponding brightness. In this case the red component was chosen because the laser was red, so it is likely that the highest intensity of the luminance components of the pixels will be in the red component of the image. For example, in the blue component of the image, the red laser would not be visible at all and detection would not be possible. This natural filtering ability is very desirable. In the next step the image is binarized (Figure 4). For clarity, only a part of the image is binarized, the remaining part is in shades of gray, respectively, only the red component of the image is displayed. A binarized image is an image whose pixel brightness component takes only two values of 0 and 255. This type of image is suitable for next processing either analytically or by 
neural networks. For binarization it is important that the threshold defines which pixel will be dark or which pixel will be light colored in result. The binarized image must be edited for having the profile thickness of only 1 pixel in result (Figure 5). A set of these profiles, arranged close together, creates the final profile (Figure 6) of the object and it is possible to precisely determine the position relative towards the starting position. $[7,9,10,11]$

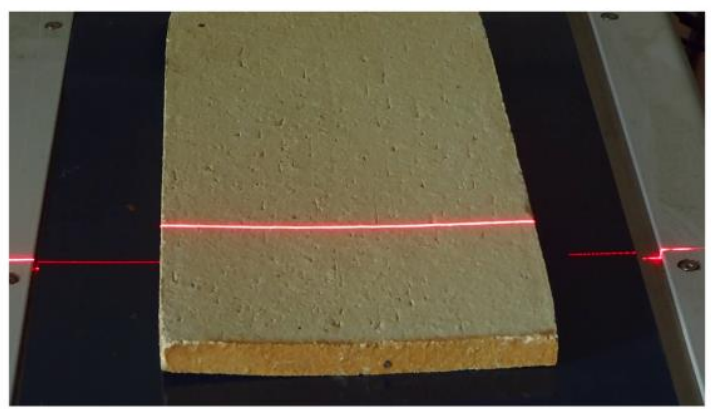

Figure 3 The original image. Source: [own processing]

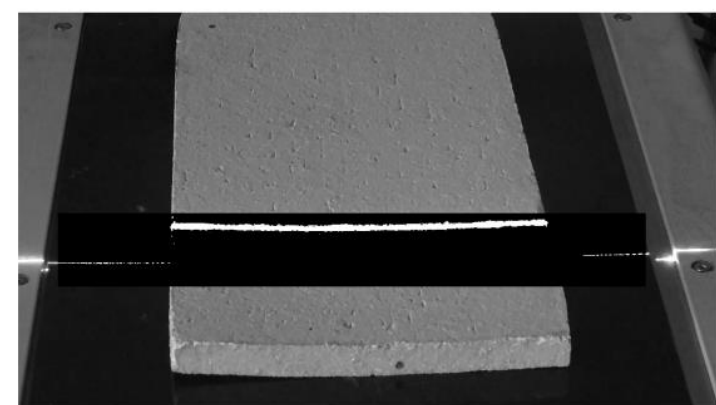

Figure 4 Binarized image. Source: [own processing]

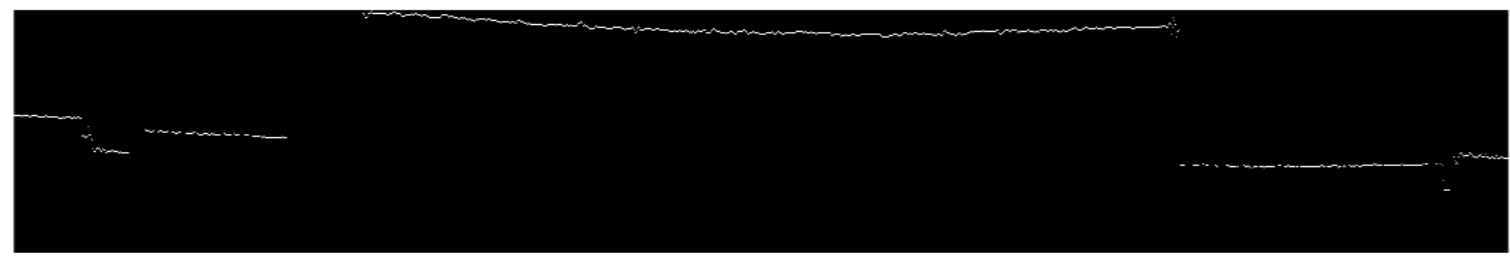

Figure 5 Extracted object profile. Source: [own processing]

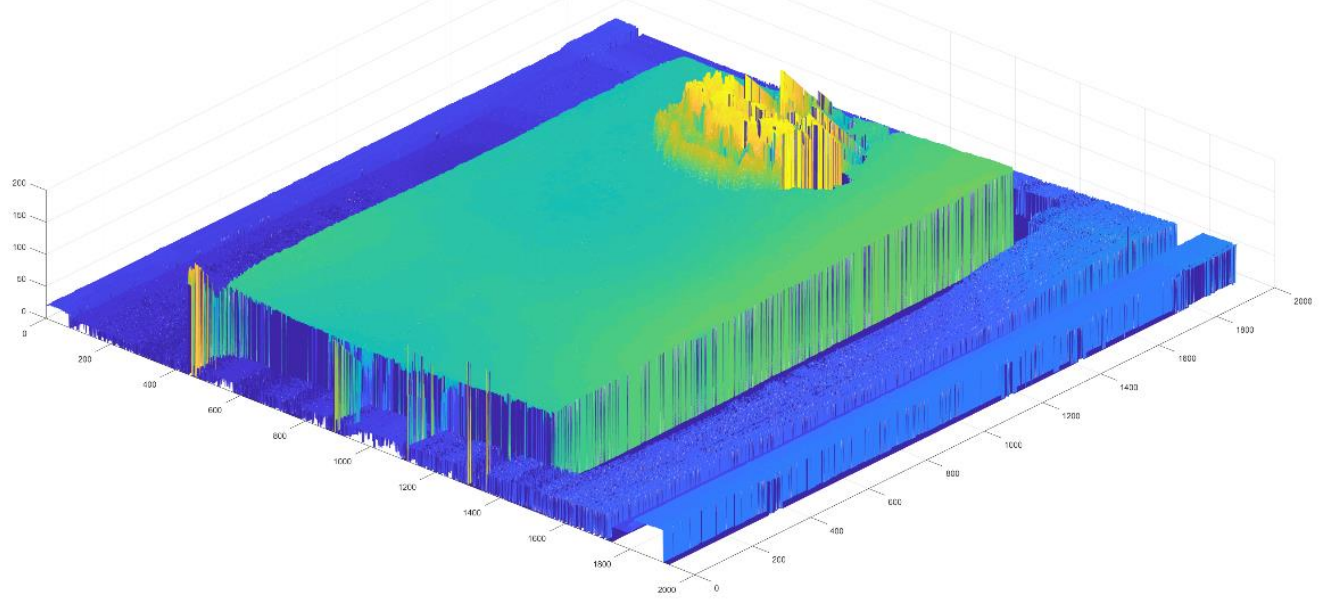

Figure 6 Stacked object profile. Source: [own processing]

\section{CONCLUSION}

The use of a camera system and artificial intelligence in the future can facilitate and optimize the production process and quality control of technological processes. With the help of a camera system with subsequent image processing, a simple evaluation of the positioning of the transporting wagon can result. The support of the camera system will be based on strict edge detection by our own algorithms, which will guarantee accurate and fast determination of the position of the face of the rolled profile before entering the rolling mill stand. 
Standard camera systems in this case fail mainly due to the presence of steam and the variable illumination of the detection scene. We have been working on evaluation algorithms for more than a year. The developed algorithms are of a robust type, with autocalibration monitoring the intensity of ambient light. The lasers used are a line type in the red and green color spectrum. By this procedure, we are able to accurately and effectively detect the profile of the rolling bar and its position relative to the inlet. The feasibility study showed that the main advantage of operation automation will be the reduction of the influence of the human factor on production processes. Other benefits will include speeding up the production process and recording it for use in any complaints. It also limits difficult work in dangerous areas.

\section{ACKNOWLEDGEMENTS}

The work was supported by the specific university research of Ministry of Education, Youth and Sports of the Czech Republic No. RPP2021/50 and SP2021/71 and SP2021/23.

\section{REFERENCES}

[1] KOLMOGOROV, V.L. Mechanika tváření kovů. Staryj Oskol: TNT, 2017

[2] PANJKOVIC, V. Friction and the Hot Rolling of Steel. Boca Raton: CRC Press, 2014.

[3] LUNEV, V.A. Tváření kovů. Leningrad, 1975.

[4] VITHANAGE, R.; HARRISON, C.; DESILVA, A. A Study on Automating Rolling-stock Maintenance in the Rail Industry using Robotics. In Proceedings of the 14th International Conference on Informatics in Control, Automation and Robotics. Madrid: ICINCO, 2017, pp. 278-283.

[5] DAVID, J., SVEC, P., GARZINOVA, R., KLUSKA-NAWARECKA, S., WILK-KOLODZIEJCZYK, D., REGULSKI, K. Heuristic modeling of casting processes under the conditions uncertainty. In Archives of civil and mechanical engineering. London: SPRINGERNATURE, 2016, pp. 179-185.

[6] GONZALEZ, R., WOODS, R. Digitální zpracování obrazu. Moskva: Technosphera, 2012.

[7] KISHORE, P.V.V.; RAGHAVA, Prasad Ch. Train Rolling Stock Intelligent Monitoring with Computer Vision. In 5th International Conference of Materials Processing and Characterization (ICMPC 2016). Amsterdam: Elsevier, 2017, pp. 1730-1739.

[8] DAVID, J., SVEC, P., PASKER, V., GARZINOVA, R. Usage of Real Time Machine Vision in Rolling Mill. Sustainability. Basel: MDPI, 2021, no. 3851.

[9] GREGOR, Michal. Detektory objektů v obraze a jejich realizace. Brno, 2008. Bakalářská práce. Vysoké učeni technické v Brně.

[10] CARAYANNIS, G. Artificial Intelligence and Expert Systems in the Steel Industry. In JOM - The Journal of The Minerals, Metals \& Materials Society (TMS). 1993, pp. 43-51.

[11] DAVID, J., GARZINOVA, R., BARCAK, T., SLACALA, J., SHMELEVA, N. Digitization of embossed numbers on continuous steel casting billets. In 28th international conference on metallurgy and materials. Brno: TANGER Ltd, 2019, pp. 1892-1897. 